\title{
Modeling and Analysis of Tractor Trolley Axle Using Ansys
}

\author{
P.Manasa ${ }^{1}$, C.Vijaya Bhaskar Reddy ${ }^{2}$ \\ ${ }^{I}$ Department of Mechanical Engineering, P.G Student, Srikalahasteeswara Institute of Technology, Srikalahasti, \\ ${ }^{2}$ Sr.Asst.Prof, Department of Mechanical Engineering,
}

\begin{abstract}
Tractor trolley (or) trailers are very popular and cheaper mode of goods and transport in rural as well as urban areas. In India, various small scale industries are adopting the crude methodologies for designing and manufacturing machine components. One such industry producing tractor trolleys for agricultural use has been identified for this study. In this paper a static analysis is conducted on a tractor trolley axle. The solid modeling of axle is developed by CATIA-V5. Analysis is done using ANSYS work bench. Most of the tractor trolley axle used today is rectangular cross section type which in turn leads to increase in the weight of tractor trolley and axle. In this paper an attempt has made by replacing rectangular cross section with circular section which result in reducing the weight of the axle and the cost.
\end{abstract}

Keywords: ANSYS, CATIAV5, OPTIMIZATION, STRESS ANALYSIS.

\section{Introduction}

In the present market scenario, cost reduction technique is playing a signified role to meet the competition in the market. Weight reduction and simplicity in design are application of industrial engineering etc., are used as source of technique. Various components or products used in rural areas are mostly manufactured in small scale industries such as farming machinery, thrashers, tractor trolleys etc .It has been observed that these rural products are not properly designed. Tractor trolleys are manufactured in small to moderate scale industries. Though tractor trolleys are manufactured of various capacities by various industries, still there is a large variation in manufacturing methods, component design etc.

The trolley axle is a central shaft for rotating wheels. The wheels are fixed to the axle, with bearings or bushings provided at the mounting points where the axle is supported. The axle maintains the position of the wheels relative to each other and to the vehicle body.

Harish v. kotare et. al [1] analyzed redesigning of tractor trolley axle using ANSYS. Their tractor trolley axle is modeled using CATIAV5 as a tool. Minimum cross section for the axle is calculated which resulted in the $24.8 \%$ reduction in the weight of the axle which comparatively smaller than the old axle. Sanjay Aloni et. al [2] performed comparative evaluation of tractor trolley axle by using finite element analysis approach. In this paper finite element analysis approach is used to modify existing rear axle of tractor trolley. Fatigue failure of the rear axle finite element model was predicted after the dynamic load was imposed on it. The finite element analysis of existing rear axle of tractor trolley revealed the stress distribution on rear axle. Finally they modified the design of existing rear axle along with change of material. Happy Bansal et.al [3] performed weight reduction and analysis of trolley axle using ANSYS. In this paper tractor trolley axle is modeled using ANSYS12.0 as a tool. They conclude that the weight of the axle is reduced to $11.5 \%$ comparatively smaller than the old axle .O. Asi et. al [4] performed fatigue failure of a rear axle shaft of an automobile. This paper describes the failure analysis of a rear axle shaft used in an automobile which has been involved in an accident. In this spectrum analysis and micro hardness measurement revealed that the failed axle shaft material was AISI 4140 steels hardened. The micrograph showing crack and overload fracture region are presented.

\section{Modeling}

In the present study an existing tractor trolley axle is selected and its dimension is noted. The possible loads acting and the place of loads are noted. According to the dimensions tractor trolley axle is modeled using CATIAV5 software and their specification are shown in table1. It is then imported to design modeler of ANSYS workbench.fig $1 \& 2$ shows imported models of rectangular and circular tractor trolley axle. 


\begin{tabular}{|c|c|c|}
\hline 1. & $\begin{array}{c}\text { Overall length of } \\
\text { Trolley }\end{array}$ & $4880 \mathrm{~mm}$ \\
\hline 2. & $\begin{array}{c}\text { Overall width of } \\
\text { trolley }\end{array}$ & $2290 \mathrm{~mm}$ \\
\hline 3. & $\begin{array}{c}\text { Overall height of } \\
\text { trolley }\end{array}$ & $1780 \mathrm{~mm}$ \\
\hline 4. & pay load & $80 \mathrm{KN}$ \\
\hline 5. & Unloaded weight & $25 \mathrm{KN}$ \\
\hline 6. & $\begin{array}{c}\text { Gross load } \\
\text { weight }\end{array}$ & $105 \mathrm{KN}$ \\
\hline 7. & Axle & $\begin{array}{c}120 \mathrm{~mm} \text { diameter of } \\
\text { length2060mm }\end{array}$ \\
\hline
\end{tabular}

Table 1: Specification of 10-tonne 4-wheeler trolley

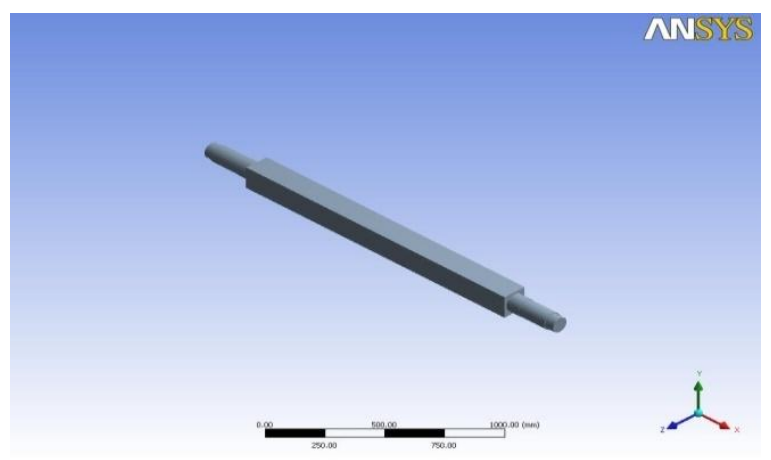

Fig 1: Modeling of Rectangular type Tractor Trolley Axle

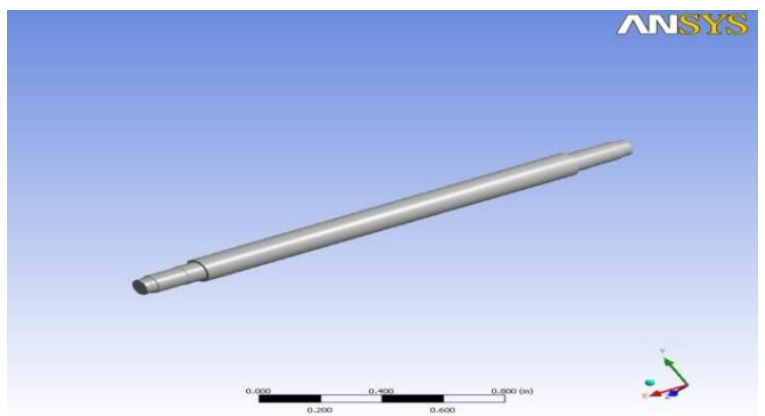

Fig 2. Modelling of Circular type Tractor Trolley Axle

\section{Material properties}

Material used for tractor trolley axle is SAE1020 and their properties as shown in the table2.

\begin{tabular}{|l|c|}
\hline \multicolumn{1}{|c|}{ Material } & SAE1020 \\
\hline Young's modulus & $2.05 \mathrm{e}+005 \mathrm{Mpa}$ \\
\hline Poisson's Ratio & 0.3 \\
\hline Density & $7.87 \mathrm{e}-006 \mathrm{~kg} / \mathrm{mm} 3$ \\
\hline Tensile yield strength & $350 \mathrm{Mpa}$ \\
\hline Tensile ultimate strength & $420 \mathrm{Mpa}$ \\
\hline
\end{tabular}

\section{Meshning:}

The next stage of the modeling is to create meshing of the created model.The below said parameters are used for meshing.

Number of Nodes: 16166

Number of elements: 8758 


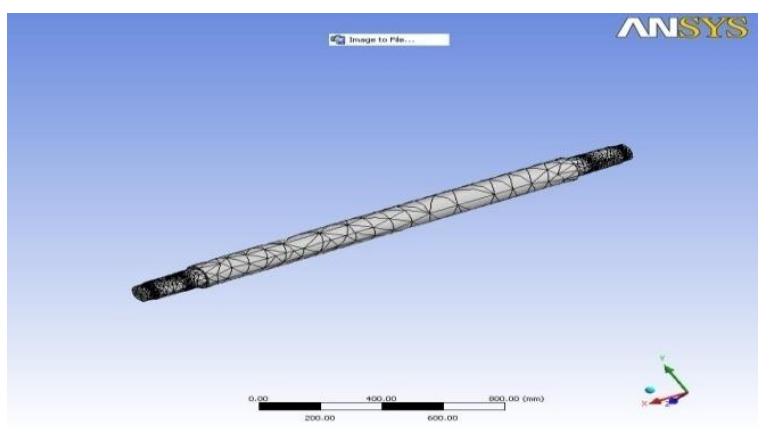

Fig 3.Meshing of Tractor Trolley Axle

IV. Load Diagram For Tractor Trolley Axle

The load diagram for tractor trolley axle is shown in fig 3

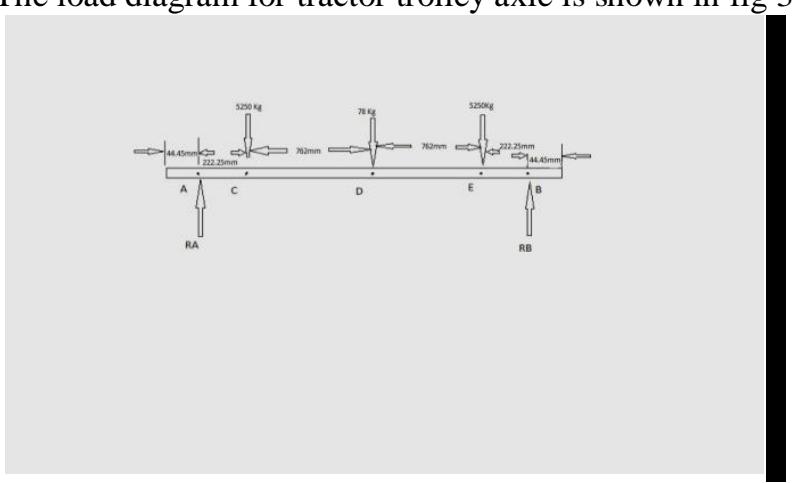

FIG 3: LOAD DIAGRAM

From below figure 4 . The point $\mathrm{A}$ is fixed and the load $52500 \mathrm{~N}$ is acting at points $\mathrm{B} \& \mathrm{C}$ and the load $780 \mathrm{~N}$ is acting at point $\mathrm{D}$.

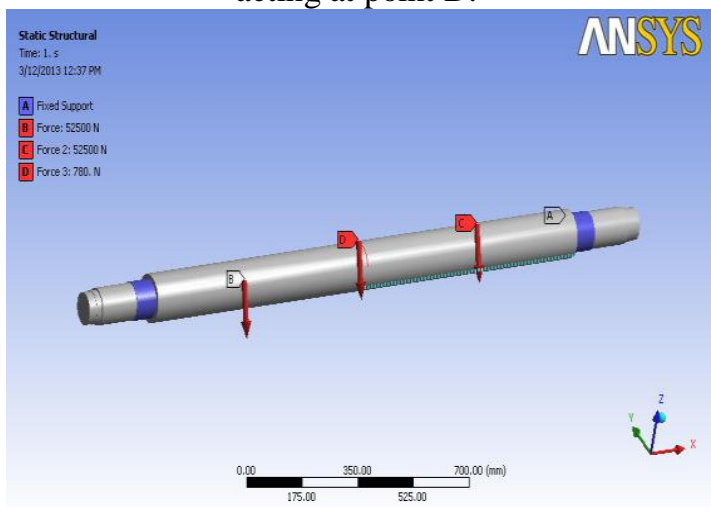

Fig 4. Load diagram of Tractor Trolley Axle 5. Results and Discussions

For the finite element analysis load are used as shown in load diagram. Fig 5.shows the equivalent(vonmisses) stress on the axle when load is applied. Red color shows the maximum stress i.e.99.399Mpa and blue color shows minimum stress i.e.1.4584e-6Mpa generated on the axle.

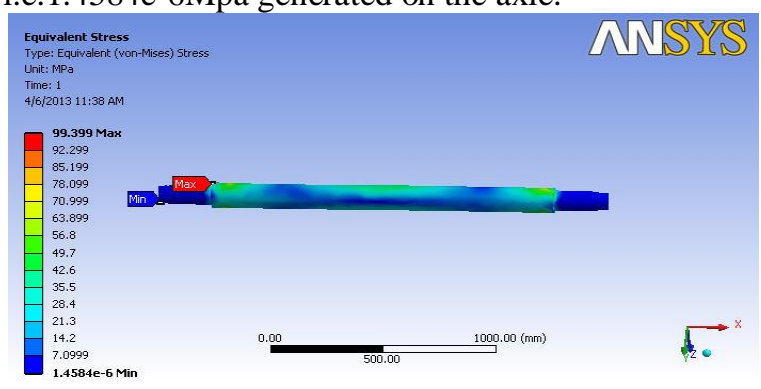

Fig 5: Von-misses stress of Tractor Trolley Axle 
Fig 6.shows the equivalent strain on the axle when load is applied. Red color shows the maximum strain i.e.0.00048487 and blue color shows minimum strain i.e.7.114e-12 generated on the axle.

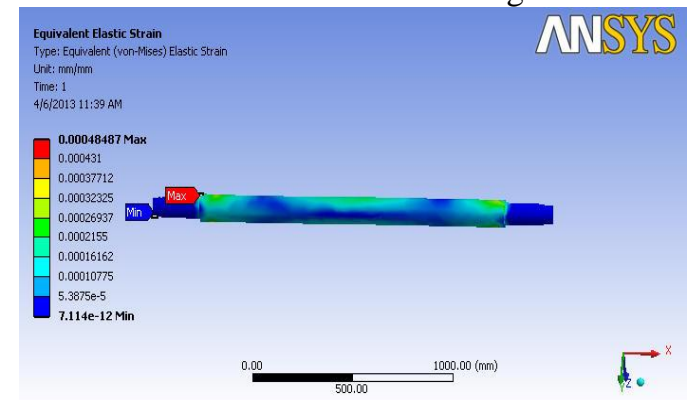

Fig 6:Equivalent Elastic Strain of Tractor Trolley Axle

Fig 7.shows the total deformation on the axle when load is applied. Red color shows the maximum deformation i.e. $0.55864 \mathrm{~mm}$ and blue color shows minimum deformation generated on the axle.

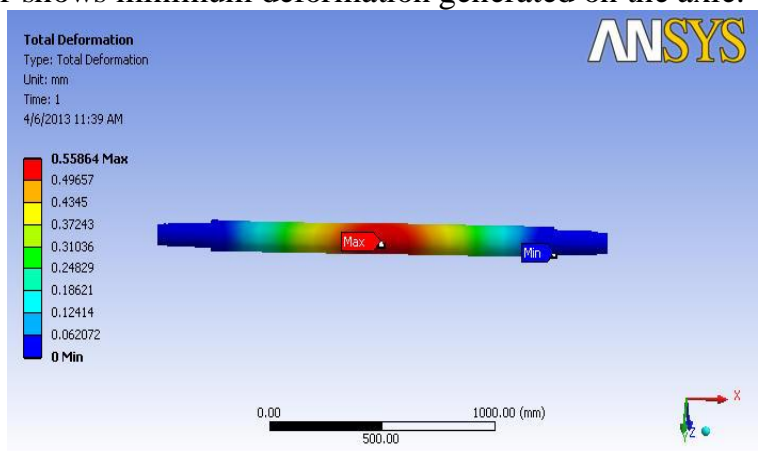

Fig 7: Total Deformation Tractor Trolley Axle

Fig 8.shows factor of safety on the axle when load is applied. Blue color shows the maximum factor of safety and red color shows minimum factor of safety generated on the axle.

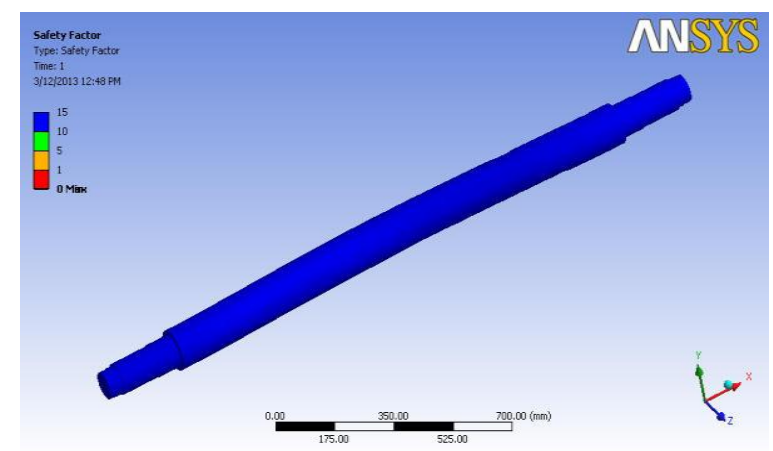

Fig 8: Factor of safety of Tractor Trolley Axle

\section{Conclusion}

In this study $40 \%$ of the weight of the tractor trolley axle is reduced due to rectangular cross section is replaced by circular cross section. From the results it can be concluded that stress induced in the tractor trolley axle is less than the allowable stress (i.e.,430 Mpa).so the design is safe under given loading condition. The results are shown in table $3 \& 4$.

\begin{tabular}{|l|l|}
\hline $\begin{array}{l}\text { Mass of Rectangular } \\
\text { type of the axle }\end{array}$ & $200.25 \mathrm{~kg}$ \\
\hline $\begin{array}{l}\text { Mass of circular type of } \\
\text { the axle }\end{array}$ & $160.13 \mathrm{~kg}$ \\
\hline $\begin{array}{l}\text { Allowable bending stress } \\
\text { of SAE1020 }\end{array}$ & $430 \mathrm{Mpa}$ \\
\hline
\end{tabular}


TABLE 3

\begin{tabular}{|l|c|c|}
\hline \multicolumn{1}{|c|}{ Name } & Maximum & Minimum \\
\hline $\begin{array}{c}\text { Von-misses } \\
\text { stress }\end{array}$ & $99.399 \mathrm{Mpa}$ & $1.4584 \mathrm{e}-6 \mathrm{Mpa}$ \\
\hline Elastic Strain & $4.8487 \mathrm{e}-4$ & $7.114 \mathrm{e}-12$ \\
\hline $\begin{array}{l}\text { Total } \\
\text { Deformation }\end{array}$ & $0.55864 \mathrm{~mm}$ & 0 \\
\hline Factor of safety & 15 & 0 \\
\hline
\end{tabular}

TABLE 4: Static analysis results of circular axle

\section{References}

[1] Harish V. Katore, Santosh B. Jaju,'Redesiginig of Tractor Trolley Axle Using Ansys", IJEST, Vol 3, Issue 6, June 2011.

[2] Sanjoy Aloni, Sandip Khedkar, "Comparative Evaluation Of Tractor Trolley Axle By Using FEM Approach", IJEST, Vol 4, Issue 4, April 2012

[3] Happy Bansal, Sunil Kumar," Weight Reduction And Analysis Of Trolley Axle Using Ansys", IJEMR, Vol 2, Issue 6, December 2012.

[4] Osman Asi, "Fatigue Failure Of Rear Axle Shaft Of an Automobile," Vol 13 Feb 2006. 